\title{
Plexiform Multicystic Ameloblastoma in a 20-Year-Old Adult
}

\author{
Kartika L. Borra ${ }^{1}$, Rahul R. Bhowate², Vidya K. Lohe ${ }^{3}$ \\ ${ }^{1}$ Department of Oral Medicine and Radiology, Sharad Pawar Dental College, DMIMS (DU), Wardha, Maharashtra, India. \\ ${ }^{2}$ Department of Oral Medicine and Radiology, Sharad Pawar Dental College, DMIMS (DU), Wardha, Maharashtra, India. \\ ${ }^{3}$ Department of Oral Medicine and Radiology, Sharad Pawar Dental College, DMIMS (DU), Wardha, Maharashtra, India.
}

\section{PRESENTATION OF CASE}

A 20 years old male patient reported to dental OPD with a complaint of swelling in the lower left back tooth region of jaw since 4 months. Patient gave a history of gradual increase in swelling from 4 months which was associated with dull aching type of pain. There was no history of trauma, balm application or pus discharge from the swelling. The patient had pain while chewing hard food and experienced an abnormal sensation over the left cheek region. There was no history of tooth removal in the same region from past 4 months. His past medical history was not significant. He was a known betel nut chewer. Extra oral examination (figure 1) revealed an illdefined, single, diffused swelling present in in lower third on left side of the face extending anteroposteriorly from left preauricular region to ala of nose. S/I from Frankfort horizontal plane to left submandibular region measuring about $7 \times 8 \mathrm{cms}$. On palpation, local temperature was raised. Swelling was non tender and was firm in consistency. Intra oral examination (figure 2) in the left lower posterior buccal vestibule showed an ill-defined solitary swelling extending anteroposteriorly from 34 to the retromolar region. Mediolaterally it extended from $1 \mathrm{~cm}$ lingual to molars to left buccal surface of molars with smooth surface. The mucosa overlying the swelling was stretched and was similar to the colour of adjacent mucosa. Palpatory findings revealed a non-tender swelling which was hard in consistency and it showed expansion of buccal and lingual cortical plate. There was superior migration of 37, 38 along with swelling. A single left submandibular lymph node was enlarged having 1.5 $\mathrm{x} 1.5 \mathrm{~cm}$ size and was non-tender. Considering the clinical findings and location of the swelling, Ameloblastoma was thought as provisional diagnosis due to its most commonly occurring nature in the mandibular molar-ramus region. In differential diagnosis ameloblastic fibroma, odontogenic keratocyst, odontogenic myxoma, were considered

Radiographic investigations include orthopantomogram (OPG) and CT. OPG (figure 3) revealed a single well defined multilocular radiolucency on left posterior region of jaw with buccal cortical plate expansion. There was Resorption of roots with 36, 37 and 38. CT (figure 4) and three-dimensional CT (figure 5) showed lytic expansile lesion of the body and ramus of left mandible with cortical thinning and loss of integrity. There was no evidence of any calcification. Routine hemogram was performed, and all the blood indices were within normal limits. Biopsy was done and histopathological examination (figure 6) showed that the ameloblast like tumour cells are arranged in irregular islands like a network of interconnecting strands. The stellate reticulum is much less prominent Moderate amount of vascularity was noted in the connective tissue stroma histologically confirming the variant of plexiform Ameloblastoma. Surgical resection of the tumour (figure 7) was done under general anaesthesia and an obturator was given after fabrication over the surgical site postoperatively to facilitate healing. Follow up of patient showed complete healing after 2 months (figure 8).

\author{
Corresponding Author: \\ Kartika Borra, \\ Radhikabai PG Girls Hostel, \\ DMIMS (DU), Sawanagi (M), \\ Wardha-442001, Maharashtra, India. \\ E-mail: karthika.bora@gmail.com
}

DOI: $10.14260 /$ jemds/2020/192

Financial or Other Competing Interests: None.

How to Cite This Article:

Borra KL, Bhowate RR, Lohe VK. Plexiform multicystic ameloblastoma in a 20-year-old adult. J. Evolution Med. Dent. Sci. 2020;9(11):894-896, DOI:
Submission 10-01-2020,

Peer Review 23-02-2020,

Acceptance 29-02-2020,

Published 16-03-2020. 


\section{DISCUSSION}

Ameloblastoma is a benign locally invasive epithelial odontogenic tumour accounting for $1 \%$ of all tumours and cysts arising in the jaws. It is commonly found in the third and fourth decade in the molar ramus region of the mandible. Among all types of ameloblastoma, multicystic ameloblastoma is believed to be locally aggressive lesion that has the tendency for recurrence. In this report we present a large multicystic ameloblastoma in the left body-ramus region of the mandible in a 20-year-old man. This large lesion was diagnosed with the help of CT and was successfully managed by hemi mandibulectomy followed by reconstruction using iliac crest bone. Ameloblastoma is the second commonest odontogenic and benign tumour of the jaws in head and neck region. It constitutes about $1 \%$ of all cysts and tumours of the jaws, 1,2 often presents as a painless, slow growing, locally aggressive tumour causing expansion of the cortical bone which is asymptomatic in most cases and further may lead to perforation of the buccal and lingual cortical plate and infiltration of the soft tissues. Population in third and fourth decade of life are mostly affected but it can also be found in any age group with no gender predilection.1-3 The ratio of occurrence of maxilla to mandibular lesions are reported to be varying from $99-1 \%$ to $80-20 \%$. Majority of ameloblastomas in the mandible are found to occur in the molar-ramus region.1,3 The purpose of this paper is to present a case of unique diffuse multicystic form of plexiform ameloblastoma that has occurred in the $2^{\text {nd }}$ decade of life.

Ameloblastoma is a type of true neoplasm of enamel organ tissue which failed to undergo differentiation during enamel formation stage. Robinson described it as unicentric nonfunctional, anatomically benign, intermittent in growth \& is persistent clinically. ${ }^{4}$ It was first coined as 'Adamantinoma' by Malassez in 1885. The term Adamantinoma was replaced by Ameloblastoma by Churchill in 1934. Sriram and Shetty RP, 5 based on an Indian Institutional study, reported it to be most common odontogenic neoplasm in India. Ameloblastoma accounted for $60.3 \%$ of all odontogenic tumours in Indian population, with an average age of presentation of 30.2 years with a slight male predilection6 ${ }^{6}$. Its etiological factor is thought to be due to the alterations and mutations in the genetic material of cells that are embryologically pre-programmed for development of tooth. ${ }^{7}$ The tumour conceivably may be derived from Cell rests of Malassez, epithelial layer of odontogenic cyst, basal cells of surface epithelium of jaws, or due to disturbance of the developing enamel organ or heterotrophic epithelial layers in other parts of jaws especially pituitary gland. ${ }^{8}$ Clinical presentation generally depicts average age of 30-39 years and shows no sex predilection. Only $20 \%$ of ameloblastomas occur in maxilla while $80 \%$ occur in the mandible mainly the third molar region. In case of mandible, molar -angle -ramus region is three times more commonly involved compared to premolar and anterior region. It is a locally invasive and slow growing tumour which can progress to great size and cause facial asymmetry, malocclusion, displacement of teeth and pathologic fractures. ${ }^{9}$ Radiographical features suggests that most lesions develop in the molar ramus region of the mandible which can extend to the symphyseal region. The lesion in many cases shows a welldefined cortical border. Internally lesion varies from totally radiolucent to mixed with the presence of bony septa creating internal compartments, providing a honey comb or soap bubble patterns.It might cause extensive root resorption and apical displacement of tooth. ${ }^{10}$
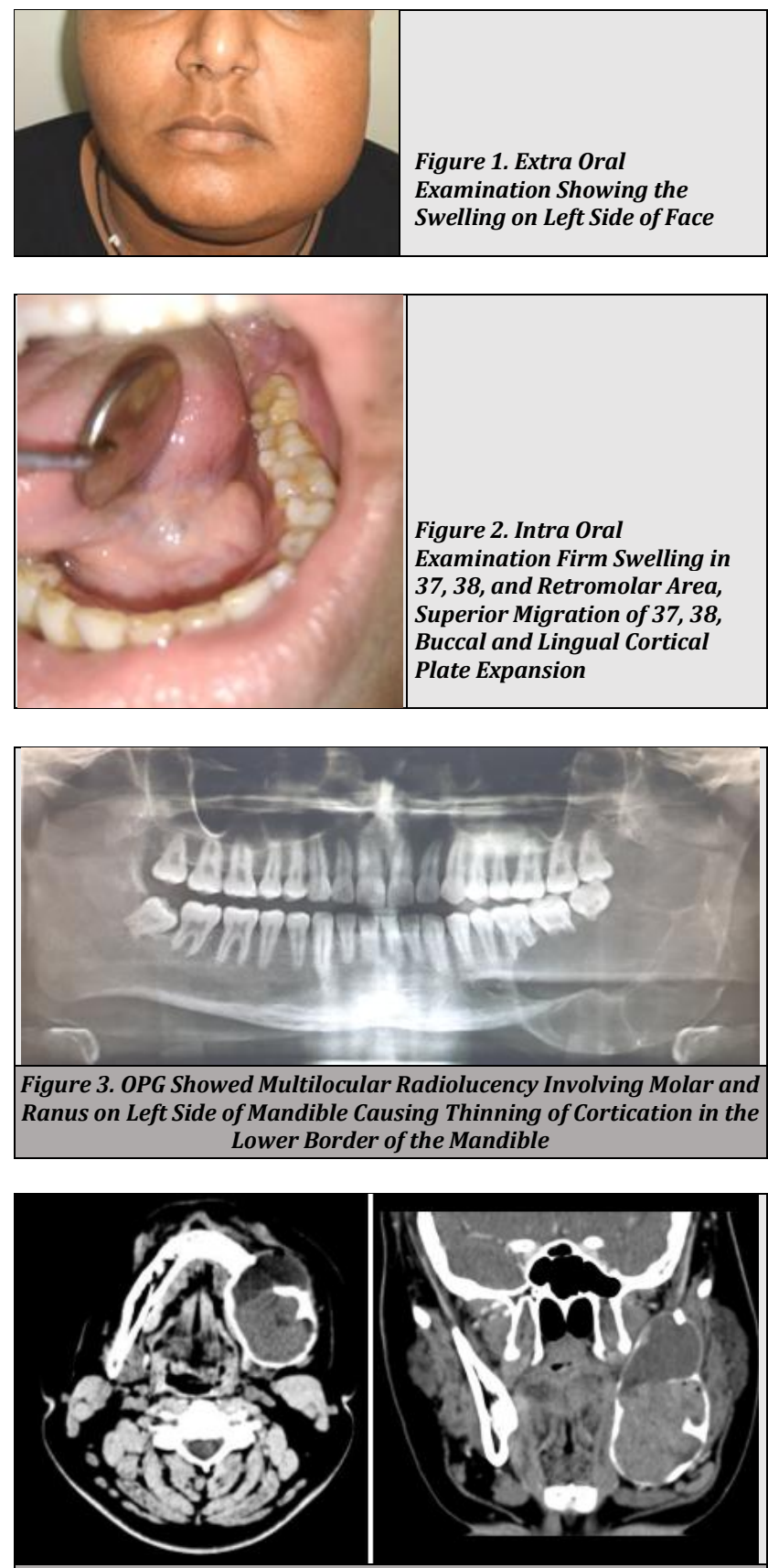

Figure 4. Axial and Coronal View CT Showing Extent of the Lesion

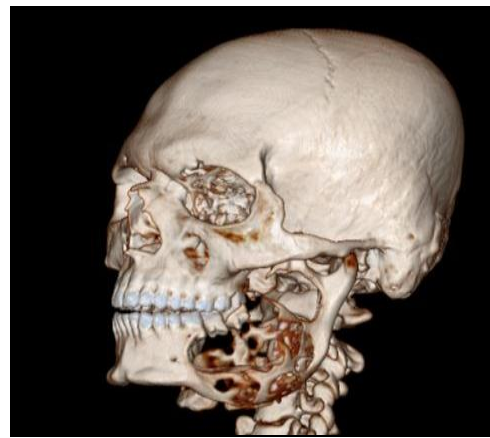

Figure 5. Three

Dimensional CT Showing

Expansion and Perforation

of Buccal and Lingual Cortical Plates 

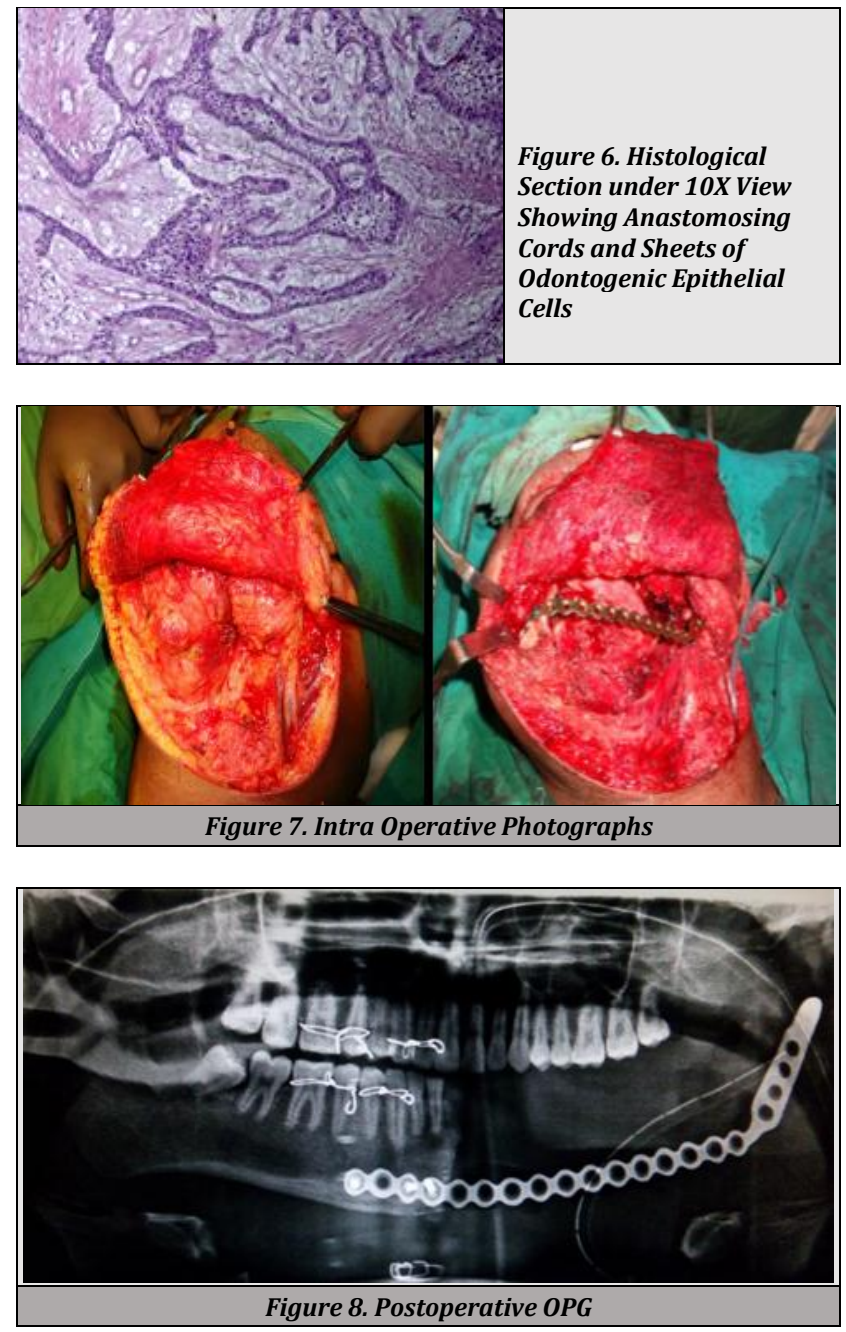

Histopathologically six subtypes have been identified in Ameloblastoma and they are Follicular, Plexiform, Acanthomatous, Basal cell, Granular cell and Desmoplastic variants. The follicular variant of ameloblastoma showed highest rate of recurrence of $29.5 \%$ followed by the plexiform variant which had a $16.7 \%$ recurrence rate. The acanthomatous type of ameloblastoma compared to the above two has a low recurrence rate of $4.5 \%$. Other variant types are rare. ${ }^{11}$ Suwarna Bhalerao et $\mathrm{al}^{12}$ emphasized the importance of the radiographic evaluation before undergoing surgical evaluation using $\mathrm{OPG}, \mathrm{CT}$, and $3 \mathrm{D}$ CT to know the proper extensions of the lesion and involvement of surrounding structures. Treatment of ameloblastoma depends on the size of lesion, its involvement in surrounding structures, etc., Small lesion may be removed by intraoral approach whereas large lesions may require resection of the jaw using various modalities like radical \&, chemical \& electrocautery, radiation therapy or combination of radiation \& surgery.

\section{CONCLUSIONS}

When the ameloblastic tumour focus penetrates the adjacent tissue from the wall of the cyst it shows a strong propensity of recurrence. Adequate radical resection of plexiform ameloblastomas is important to avoid further complications and recurrence. Long-term follow-up of the patient is an absolute necessity, regardless of the form of treatment.

\section{REFERENCES}

[1] Kahairi A, Ahmad RL, Islah WL, et al. Management of large mandibular ameloblastoma-a case report and literature reviews. Arch Orofac Sci 2008;3(2):52-5.

[2] Giraddi GB, Bimleshwar, Singh C, et al. Ameloblastomaseries of 7 treated cases-and review of literature. Arch Oral Sci Res 2011;1:152-5.

[3] Vohra FA, Hussain M, Mudassir MS. Ameloblastomas and their management: a review. Pak J Surg 2009;2013:13642.

[4] Rajendran A, Sivapathasundharam B. Odontogenic tumors: Shafer's Textbook of Oral pathology. $7^{\text {th }}$ edn. Elsevier India 2014: p. 1147-55.

[5] Sriram G, Shetty RP. Odontogenic tumors: a study of 250 cases in an Indian teaching hospital. Oral Surg Oral Med Oral Pathol Oral Radiol Endod 2008;105(6):e14-21.

[6] Krishnapillai R, Angadi PV. A clinical, radiographic and histologic review of 73 cases of ameloblastoma in an Indian population. Quintessence Int 2010;41(5):e90-100.

[7] Kumamoto H. Molecular pathology of odontogenic tumors. J Oral Pathol Med 2006;35(2):65-74.

[8] Cherrick HM. Odontogenic tumors of the jaw. In: Laskin DM, edr. Oral and maxillofacial surgery. New Delhi, India: AITBS Publishers 2009: p. 626-36.

[9] Becelli R, Carboni A, Cerulli G, et al. Mandibular ameloblastoma: analysis of surgical treatment carried out in 60 patients between 1977 and 1998. J Craniofac Surg 2002;13(3):395-400.

[10] Langland RP, Langland OE, Nortje CJ. Diagnostic Imaging of the Jaw. $1^{\text {st }}$ edn. Philadelphia, Pa, USA: Williams \& Wilkins 1995.

[11] Reichart PA, Philipsen HP. Textbook of Odontogenic tumors and allied lesions. Quintessence Publishing 2004: p. 320-7.

[12] Bhalerao SM, Lohe VK, Bhowate RR, et al. Plexiform unicystic ameloblastoma: a rare variant of ameloblastoma. J Datta Meghe Inst Med Sci Univ 2017;12(4):284-8. 